(c) 2017 IEEE. Personal use of this material is permitted. Permission from IEEE must be obtained for all other uses, in any current or future media, including reprinting/republishing this material for advertising or promotional purposes, creating new collective works, for resale or redistribution to servers or lists, or reuse of any copyrighted component of this work in other works.

Digital Object Identifier (DOI): 10.1109/PTC.2017.7981037

PowerTech, 2017 IEEE Manchester

Decentralized reactive power and voltage control of wind farms with type-4 generators

Shahab Asadollah

Rongwu Zhu

Marco Liserre

Costas Vournas

Suggested Citation

S.Asadollah, R. Zhu, M. Liserre and C. Vournas, "Decentralized reactive power and voltage control of wind farms with type-4 generators," 2017 IEEE/PES Powertech, pp. 1-6, June 2017. 


\section{Decentralized Reactive Power and Voltage Control of Wind Farms with Type-4 Generators}

\author{
Shahab Asadollah \\ Rongwu Zhu \\ Marco Liserre \\ Chair of Power Electronics \\ Christian Albrechts University of Kiel \\ Kiel, Germany \\ sha@tf.uni-kiel.de
}

\author{
Costas Vournas \\ School of Electrical and Computer Engineering \\ National Technical University of Athens \\ Athens, Greece \\ vournas@power.ece.ntua.gr
}

\begin{abstract}
Due to the growing penetration of wind energy into the power grid, wind power must play a more active role in grid operation and control. A decentralized wind farm power control scheme focusing on reactive power and voltage control is presented in this paper. Compared to the popular Centralized Power Control (CPC) schemes, this solution is cheaper, more reliable and needs less installation effort, because there is no need for the central control unit, measurement sensors at the Point of Common Coupling (PCC) and communication infrastructure. Moreover, contrasting the CPC solutions, communication problems do not degrade the system performance. In this method required values at $\mathrm{PCC}$ are calculated with the help of a two-port wind farm model, afterwards these values are used to correct the reactive power set point of each converter to satisfy grid code requirements at PCC. Finally, the correctness of the proposed control strategy is validated by simulation results.
\end{abstract}

Index Terms-Decentralized Control - Reactive Power Control Voltage Control - Wind Farm Control

\section{INTRODUCTION}

As the penetration of wind energy into the power grid increases, wind power must play a much more active role in grid operation and control. Thus, many power system operators have strict grid connection requirements for behaviors of wind power systems [1] and demand an operational behavior and controllability similar to conventional power plants. This paper focuses on the generators with full scale converters (Type-4) because they provide a smooth grid connection for the entire speed range [2]. As the requirements should be satisfied at the point of common coupling (PCC), the whole wind farm should be considered as a single unit. To realize the required control tasks various control strategies are developed. An overview of wind farm control strategies is provided in [3]. A common solution to control a wind farm is the Centralized Power Control (CPC) deploying two hierarchical control levels. The lower level is the wind turbine control, a local controller for each wind turbine to control the power generation at wind turbine level, and at upper level, there is the wind farm control, a central control unit to control the wind farm at wind farm level. In CPC besides the central control unit, measurement sensors at PCC and communication means are required. Moreover, the communication delay or data loss can degrade the system performance [4]. Therefore, in this paper a decentralized wind farm control scheme focusing on reactive power and voltage control is presented. In this control scheme the upper level control, the wind farm central control unit, is removed. Plus, no measurement sensors at PCC and communication infrastructure are required. The essential values at PCC are calculated by implementing the model of the wind farm transformers and cables into converter controllers. By using these models each converter controller can correct its own reactive power set point to compensate the reactive power demand of the cables and transformers and meet the grid code requirements at PCC.

\section{CENTRALIZED Wind FARM POWER CONTROL}

For the centralized power control solutions, two hierarchical control levels are necessary which are described in detail in the following.

\section{A. Wind Turbine Control system}

In the literature there are different control strategies for variable speed wind turbine [5]. Typically, two levels of control operations are performed by wind turbine control system. Higher level consists of turbine level supervisory control, which controls operational state transition considering the wind conditions and health of wind turbine generators. The lower level mainly includes pitch controller and converter controller [3]. Different control schemes for grid connected converters are introduced in [6]. In case of full-scale back to back converters, the converter controller, controls both generator side converter and Grid Side Converter (GSC) to follow the active power and reactive power set points. Normally the active power set point is determined by maximum power point tracking techniques or ordered by the central controller. The control of active power is outside the scope of this paper.

Since GSC is directly interfaced with the grid and plays an important role to comply with strict grid codes, this paper will mainly focus on this part of the wind power generation system. 
The active and reactive power control is realized by controlling direct and quadrature current components ( $i_{d}$ and $i_{q}$ ), respectively [7]. The injected active power to the grid is controlled by an outer dc voltage control loop generating the $i_{d}$ set point. The reactive power is controlled by setting the q-axis current reference of the current control loop. The d-axis of the synchronous reference frame is aligned to the voltage vector (voltage oriented control) by implementing the Phase Lock Loop (PLL).

\section{B. Wind Farm Control}

The wind farm controller behaves as a single central unit. It controls the power production of the whole wind farm by sending out the power references to the wind turbine control level. For the centralized control, these power references are prepared according to grid code requirements in the wind farm control level based on several measurements at PCC and the available power of each individual wind turbine. As shown in Fig. 1, wind farm controller (WF Ctrl.) determines the power set points for each wind turbine controller (WTG Ctrl.) to satisfy the system operators demands at PCC by measuring the voltage, active and reactive power at PCC. This control strategy is a close loop control thus, special attention must be paid to the effect of communication lags and data loss in designing a central wind farm controller [4].

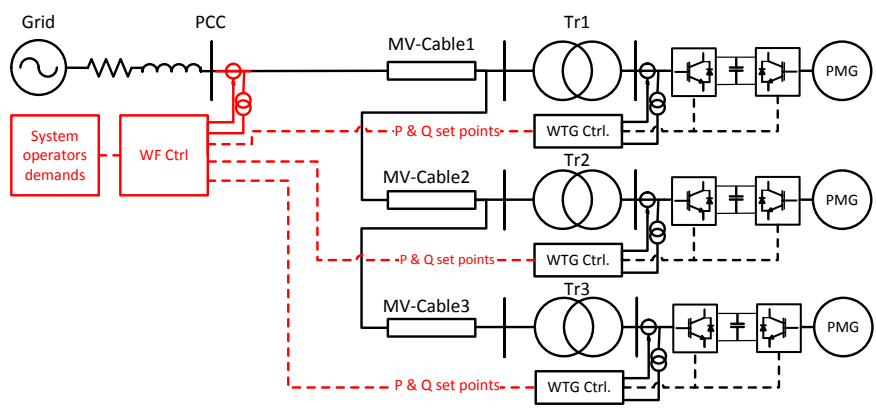

Fig. 1. Centralized control scheme

In [8] the authors address the design and implementation issues of a centralized power controller strategy of a wind farm, focusing on regulating the wind farm power production to the reference power ordered by the system operators. A comparative study on the performance of three control strategies for doubly-fed induction generator (DFIG) wind turbines, when both active and reactive power set points are ordered by the wind farm control system is presented in [9]. The important point of all these works is that the power references are produced in the wind farm control level. There are different strategies for computing active and reactive power references for each wind turbine. The simplest strategy is to calculate the same power references for each wind turbine [10]. A more efficient strategy is proposed in [8] where the power reference for each wind turbine is considered from a proportional distribution of the available power, so no turbine becomes overloaded. The ultimate objective of all these strategies is to ensure that the wind farm active and reactive power outputs conform to grid operator demand at PCC.

\section{DECENTRALIZED WIND FARM POWER CONTROL}

The presented decentralized wind farm control strategy focuses on reactive power and voltage control. In this proposed method, the cables and transformers connected to each generator are modeled as an approximated $\mathrm{T}$ equivalent circuit. The series and shunt parameters are calculated and parameterized in each turbine converter controller. This enables each turbine converter controller to calculate the voltage, active and reactive power at PCC. Furthermore, each turbine can correct its own reactive power set point to compensate the reactive power deviation caused by transformers and cables and achieve the desired reactive power at PCC. Consequently, the wind farm controller can be omitted if the remote control of the wind farm is not required, otherwise each turbine controller should be able to directly receive the communication signals from the grid operator containing the set points at PCC. In any case, no current and voltage sensors are required to be installed at PCC by the wind farm operator. This makes this control cheaper and more reliable. Furthermore, the negative effect of communication delay, noise and data loss is no concern. The major disadvantage of this method is the parameterization effort. Every individual converter in the wind farm should be parameterized accurately, meaning that there is a limited flexibility for future extension or structural changes in the wind farm.

\section{A. Two-Port Equivalent Circuit of the Wind Farm}

The cables and transformers between each turbine and PCC can be regarded as an approximated $\mathrm{T}$ equivalent circuit, as shown in Fig. 2 [11]. Having the precise parameters of the LVcables and transformers are necessary and the accuracy of MVcables and $\mathrm{HV}$ transformers parameters is less important because their referred impedances (to LV side) are much smaller than the impedances of the transformer and LV-cables.

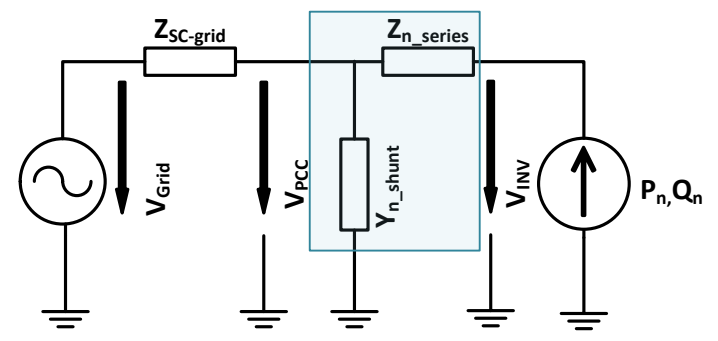

Fig. 2. Two-port equivalent circuit seen from each wind turbine

Based on [11] the active and reactive power at PCC can be stated by these equations

$$
\begin{gathered}
P_{P C C}=P_{n}-R_{n_{\text {series }}} \cdot \frac{P_{n}^{2}+Q_{n}^{2}}{V_{P C C}^{2}}-G_{n_{\text {shunt }}} \cdot V_{P C C}^{2} \\
Q_{P C C}=Q_{n}-X_{n_{\text {series }}} \cdot \frac{P_{n}^{2}+Q_{n}^{2}}{V_{P C C}^{2}}+B_{n_{-} \text {shunt }} \cdot V_{P C C}^{2}
\end{gathered}
$$

where $P_{\mathrm{n}}$ and $Q_{\mathrm{n}}$ are the p. u. active and reactive power of nth wind turbine, $P_{\mathrm{PCC}}$ and $Q_{\mathrm{PCC}}$ are the p.u. active and reactive power at PCC, $R_{\mathrm{n} \_ \text {series }}$ and $X_{\mathrm{n}_{-} \text {series }}$ are the p.u. resistance and reactance of the series impedance $Z_{n \text {-series }}$ regarding the nth 
turbine, $G_{n \_ \text {shunt }}$ and $B_{\mathrm{n} \_s h u n t_{1}}$ are the shunt conductance and susceptance of shunt admittance in p.u.

\section{B. Calculation of Series and Shunt Parameters}

The series and shunt parameters can be calculated manually or using a power flow program. Two power flow calculation are required for each turbine. One with $U_{P C C}=1$ p.u., $P_{\mathrm{n}}=0, Q_{n}=0$ to calculate the shunt parameters from (3) and (4) when all other turbines including their transformer and cables are disconnected and the other one with $U_{P C C}=1$ p.u., $P_{n}=1, Q_{n}=0$ to calculate the series parameters from (5) and (6).

$$
\begin{gathered}
G_{n_{-} \text {shunt }}=-P_{P C C} \\
B_{n_{-} \text {shunt }}=Q_{P C C} \\
R_{n_{-} \text {series }}=1-P_{P C C}-G_{n_{-} \text {shunt }} \\
X n_{\text {series }}=-Q_{P C C}+B_{n_{-} \text {shunt }}
\end{gathered}
$$

For each wind turbine these values should separately be calculated and implemented in generator converter. However, if all the transformers in the farm are similar and cable lengths are not so different, it will be possible to use the same values for all the converters. This reduces the parameterization effort significantly.

\section{Calculating the Voltage, Active and Reactive Power at PCC}

In order to meet the grid code requirements at PCC, the voltage, active and reactive power at PCC should be known. In this decentralized control method, these values are calculated using the $Z_{n_{-} \text {series }}, Y_{n_{-} \text {shunt }}$, the feed in current and inverter voltage.

Equation (7) is used to calculate voltage at PCC.

$$
V_{P C C}=\sqrt{\begin{array}{c}
\left(V_{d}+i_{d} \cdot R_{n_{-} \text {series }}-i_{q} \cdot X_{n_{-} \text {series }}\right)^{2} \\
+\left(i_{d} \cdot X_{\mathrm{n}_{-} \text {series }}+i_{q} \cdot R_{\mathrm{n}_{\text {s series }}}\right)^{2}
\end{array}}
$$

where $V_{\mathrm{d}}$ is the d-axis of inverter voltage, and $i_{\mathrm{d}}$ and $i_{\mathrm{q}}$ are the direct and quadrature axis components of inverter current.

The reactive power at $\mathrm{PCC}$ is calculated as

$$
Q_{P C C}=Q_{n}-Q_{n_{-} d e v}
$$

where $Q_{\mathrm{n} \_ \text {dev }}$ is the deviation in reactive power given by

$$
Q_{n_{-} \text {dev }}=\left(i_{d}^{2}+i_{q}^{2}\right) \cdot X_{n_{\_} \text {series }}-B_{n_{-} \text {shunt }} \cdot V_{P C C}^{2}
$$

and finally the active power at PCC is derived from (10).

$$
\begin{gathered}
P_{P C C}=P_{n}-P_{\text {nloss }} \\
P_{\text {nloss }}=R_{n \_ \text {series }} \cdot\left(i_{d}^{2}+i_{q}^{2}\right)+G_{n \_ \text {shunt }} \cdot V_{P C C}^{2}
\end{gathered}
$$

Equation (10) is accurate only if all the wind turbines in a wind farm are generating the same active power in p.u., i.e. all the individual turbines in the wind farm are similar and receive identical winds which is normally an accepted assumption and the base of many full aggregated modeling techniques of wind farm [12], [13].

\section{Reactive power set point correction}

Automatic Voltage Control (AVC), i.e. controlling the voltage in the wind farm $\mathrm{PCC}$ is one of the reactive power control function required by the system operators. This means that the wind farm must produce or absorb an amount of reactive power to compensate for the deviations in the PCC voltage. Additional reactive power control functions can be constant reactive power and constant power factor.

Generally, cables and transformers between each inverter and PCC can cause voltage drop, active and reactive power deviations. To correct the reactive power set point for each GSC, voltage at PCC and reactive power deviation between each inverter and PCC should be calculated. Fig.3 shows how the corrected reactive power set point (QCorr) for AVC function is calculated. The series and shunt parameters are stored in red blocks. "V $\mathrm{V}_{\mathrm{PCC}}$ Cal." block calculates the $\mathrm{V}_{\mathrm{PCC}}$ according to (7). The output of " $\mathrm{Q}_{\mathrm{dev}}$ Cal." block is the reactive power demand of the transformer and the cables between converter and PCC calculated by (9). V* ${ }_{\text {PCC }}$ is the voltage set point at PCC and QPCC-sp is the output of droop control and the desired PCC reactive power. For the simulations the transfer function of the "Droop Control" block is

$$
G(s)=\frac{Q_{P C C-S P}(s)}{\operatorname{Error}_{V-P C C}(s)}=\frac{\mathrm{k}_{\mathrm{p}}}{\tau \mathrm{s}+1}
$$

where Error $_{V_{-} P C C}$ is the error between calculated PCC voltage and $\mathrm{PCC}$ voltage set point, $\mathrm{k}_{\mathrm{p}}$ is the voltage droop control setting (slope) and $\tau$ is the time constant.

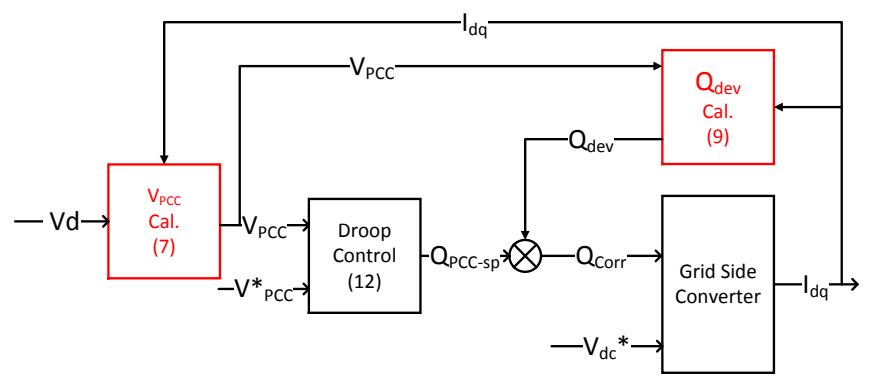

Fig. 3. Q correction realization for PCC automatic voltage control

For realizing the reactive power set point correction for constant power factor at PCC function shown in Fig. 4, active power losses should also be calculated. This is done in " $\mathrm{P}_{\text {losses }}$ Cal.” block using (11). In Fig. 4, QPCC-sp is derived by,

$$
Q_{P C C-s p}=P_{P C C} \cdot \tan \left(\operatorname{acos}\left(P F_{s p}\right)\right)
$$

This value is summed up with $\mathrm{Q}_{\mathrm{dev}}$ to form the corrected reactive power $\left(\mathrm{Q}_{\text {corr }}\right)$ required to be injected by the GSC (14).

$$
Q_{c o r r}=Q_{n_{-} d e v}+Q_{P C C-s p}
$$




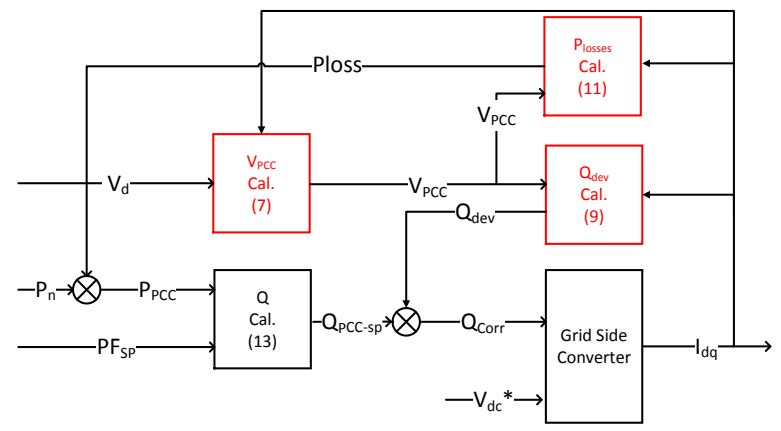

Fig. 4. Q correction realization for fixed power factor

\section{SimUlation ResUlts}

\section{A. Wind farm and wind turbines configuration}

The simulated wind farm composed of three wind turbines with permanent magnet synchronous generators controlled by full back-to-back converters is illustrated in Fig 5. In this model, a wind farm consisting of only three wind turbines is chosen to minimize the simulation time. However, the controller can also manage larger wind farms. The three phase system is assumed to be balanced. The shunt and series parameters are calculated individually for each converter by (3)-(6) and are given in p.u. in Table I. Other model parameters are listed in the Table II.

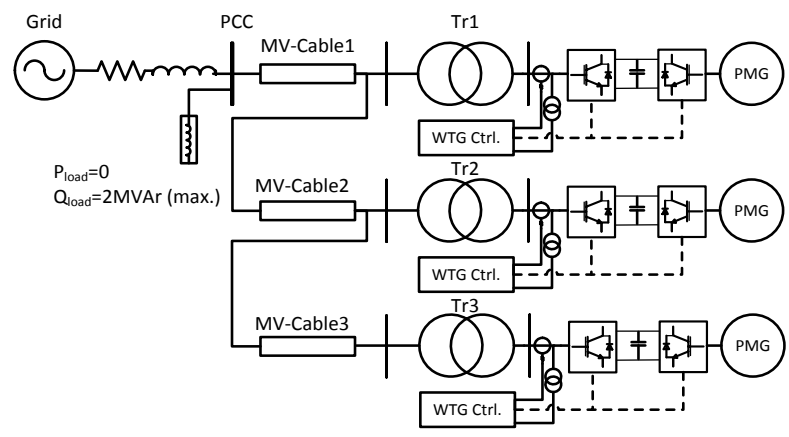

Fig 5. Wind Farm model with decentralized control scheme

TABLE I. SERIES AND SHUNT PARAMETERS

\begin{tabular}{|l|c|c|c|}
\hline Parameters & $\mathbf{n = 1}$ & $\mathbf{n = 2}$ & $\mathbf{n = 3}$ \\
\hline $\mathrm{R}_{\mathrm{n} \_ \text {series }}$ & 0.0048 & 0.0052 & 0.0055 \\
\hline $\mathrm{X}_{\mathrm{n} \_ \text {series }}$ & 0.0430 & 0.0440 & 0.0451 \\
\hline $\mathrm{G}_{\mathrm{n} \_ \text {shunt }}$ & 0.0035 & 0.0035 & 0.0035 \\
\hline $\mathrm{B}_{\mathrm{n} \_ \text {shunt }}$ & 0.0011 & 0.0022 & 0.0033 \\
\hline
\end{tabular}

\section{B. Automatic Voltage Control}

Only to demonstrate the functionality of the automatic voltage control, a fairly weak grid (with 50 MVA short circuit capacity) is connected to PCC. The pure reactive load connected to PCC as shown in Fig. 5, changes following the curve as shown in Fig. 6 to vary the PCC voltage. Also real limits for reactive power changing rates which may apply to both centralized and decentralized control are ignored and all the generators are feeding in an active power equal to 0.7 p.u..

TABLE II. Simulation Model PARAMETERS

\begin{tabular}{|c|c|c|c|}
\hline Elements & Parameters & Parameter Description & Values \\
\hline \multirow{3}{*}{ PMG } & $\mathrm{P}_{\text {rated }}$ & Rated Active Power & $2 \mathrm{MW}$ \\
\hline & $\mathrm{V}_{\text {rated }}$ & Rated Voltage & $600 \mathrm{~V}$ \\
\hline & $F_{\text {rated }}$ & Rated Frequency & $50 \mathrm{~Hz}$ \\
\hline \multirow{6}{*}{$\operatorname{Tr} 1,2,3$} & $S_{\text {rated }}$ & Rated Apparent Power & $2.5 \mathrm{MW}$ \\
\hline & $\mathrm{V}_{\text {pri }}$ & Rated Primary Voltage & $25 \mathrm{kV}$ \\
\hline & $\mathrm{V}_{\mathrm{sec}}$ & Rated Secondary Voltage & $0.6 \mathrm{kV}$ \\
\hline & uk & Short Circuit Impedance & $8 \%$ \\
\hline & $\mathrm{X} / \mathrm{R}$ & $\begin{array}{c}\text { Inductance to Resistance } \\
\text { ratio }\end{array}$ & 9.5 \\
\hline & $\mathrm{Rm}$ & Magnetization Res. & 500 p.u. \\
\hline \multirow{4}{*}{$\begin{array}{l}\text { MV- } \\
\text { Cable } \\
1,2,3\end{array}$} & $\mathrm{R}$ & $\begin{array}{c}\text { Positive Sequence } \\
\text { Resistance }\end{array}$ & $\begin{array}{c}0.1153 \\
\mathrm{Ohm} / \mathrm{km}\end{array}$ \\
\hline & $\mathrm{L}$ & $\begin{array}{l}\text { Positive Sequence } \\
\text { Inductance }\end{array}$ & $\begin{array}{c}1.053 \mathrm{e}-3 \\
\mathrm{H} / \mathrm{km}\end{array}$ \\
\hline & $\mathrm{C}$ & $\begin{array}{l}\text { Positive Sequence } \\
\text { Capacitance }\end{array}$ & $\begin{array}{c}11.33 \mathrm{e}-9 \\
\mathrm{~F} / \mathrm{km}\end{array}$ \\
\hline & Length & Cable Length & $1 \mathrm{~km}$ \\
\hline \multirow{2}{*}{ Grid } & $\mathrm{V}_{\text {grid }}$ & Grid Voltage & $20 \mathrm{kV}$ \\
\hline & $\mathrm{S}_{\text {S.C. }}$ & Short Circuit Capacity & $50 \mathrm{MVA}$ \\
\hline \multirow{2}{*}{$\begin{array}{l}\text { Droop } \\
\text { Control }\end{array}$} & $\mathrm{k}_{\mathrm{p}}$ & Voltage droop control gain & 100 \\
\hline & $\tau$ & Time constant & $0.2 \mathrm{~s}$ \\
\hline
\end{tabular}

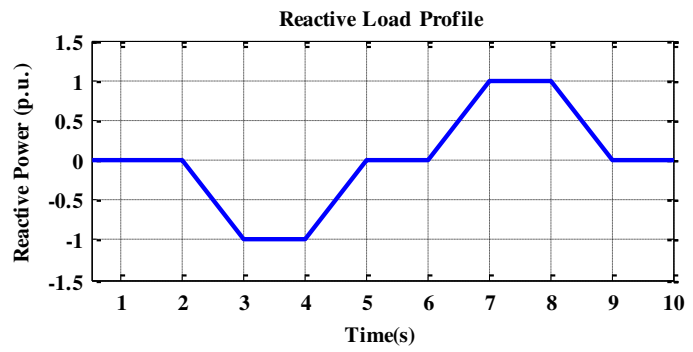

Fig. 6. The profile of the reactive load connected to PCC

The result of simulation is shown in Fig. 7. The dashed line shows the PCC voltage set point (1 p.u.). The red curve demonstrates the voltage profile when only fixed reactive power is injected by the GSC independent from PCC voltage. If the PCC reactive power set point is applied directly to converter controller (without considering the cables and transformers), the blue curve will result. The green curve demonstrates the PCC voltage profile when a perfect central controller is used and finally the black curve shows the result of the proposed decentralized control strategy in which the effects of the transformers and cables are considered. Fig. 7 clearly shows that with no voltage control, the voltage variations are largest (about 0.046 p.u.). With the decentralized control, the voltage variations are reduced and the variation can be further reduced when the effects of the transformer and cable are considered by parameterizing the wind farm model in GSC. Compared to the centralized control, although the decentralized control cannot eliminate the voltage variation completely, but it has reduced the maximum deviation to 0.0068 p.u., which can satisfy the grid code requirements and obtain high performance for the power grid. 


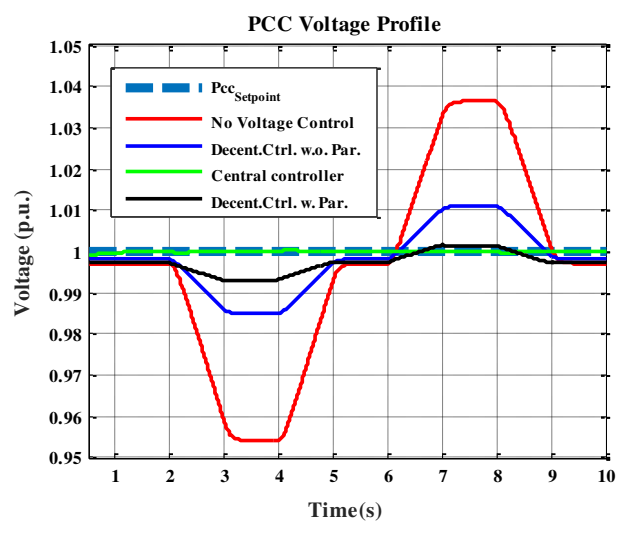

Fig. 7. PCC voltage profile

The reactive power generated by each wind turbine is depicted in Fig. 8 proving that the reactive power is not circulating among the wind turbines. However, as the parameters inaccuracy gets higher, the risk of reactive power circulation increases. This is shown in Fig. 9 where there is a positive $10 \%$ inaccuracy in all the parameters of first wind turbine and a negative $10 \%$ for the second turbine. At the spots where the slopes are opposite there is a small (less than 0.02 p.u.) reactive power circulation.

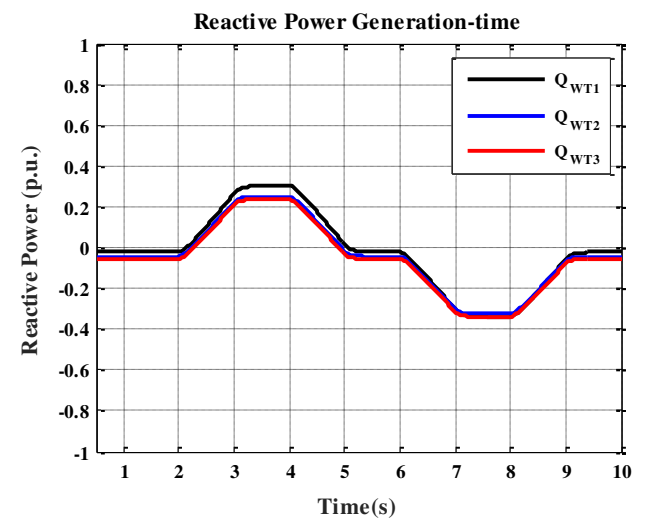

Fig. 8. The generated reactive power by each individual turbine

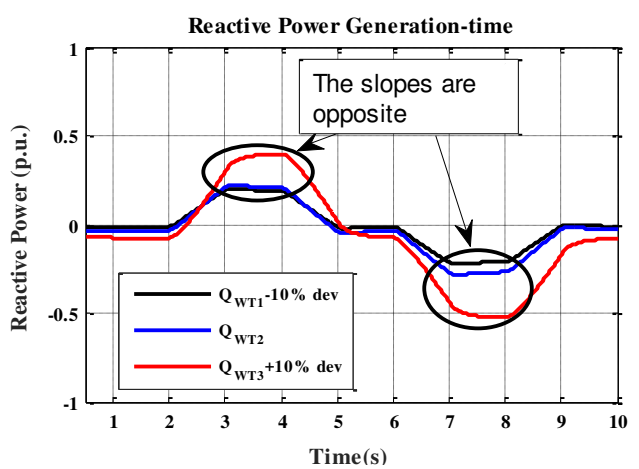

Fig. 9.Generated reactive power by each converter with a $10 \%$ inaccuracy.

\section{Fixed Power Factor}

For simulating the fixed power factor function, PCC is connected to a strong grid and there is no load at PCC. Fig. 10 demonstrates the result of the simulation. Power factor set point (dashed blue curve) changes from 0.95 overexcited to 1 and then to 0.95 underexcited. Using a central controller (green curve) the power factor is matched to the set point. The blue curve shows decentralized control without the wind farm model parameterization (max. deviation is 0.0235 ). When the effect of plant transformers and cables are not considered, power factor at PCC is higher than the set point for the overexcited set points and lower for underexcited set points, because $Q_{d e v}$ is always inductive when $P n=0.7$ p.u.. As clearly seen, implementing the farm model has reduced the max. deviation to 0.0016 which is far below the allowed error 0.005 according to German standards [14].

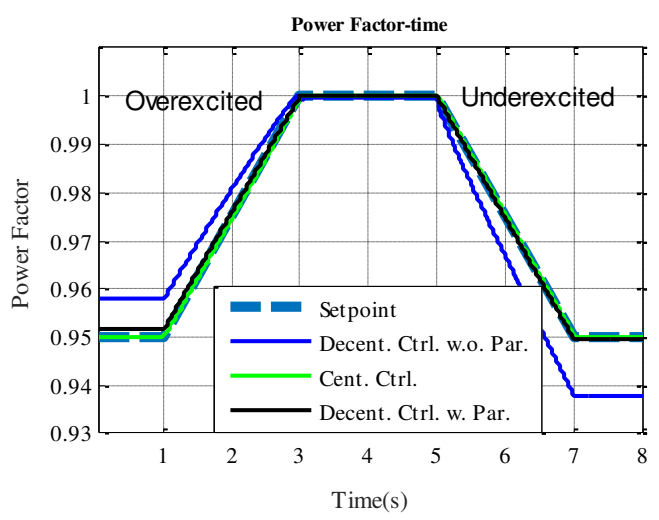

Fig. 10. Wind farm power factor at PCC

According to (10), for calculating the active power at PCC, the difference in injected active power is critical. Therefore, the influence of unequal active powers on the fixed power factor function is investigated and shown in Fig. 11. With different active power values, although $\mathrm{P}_{\mathrm{PCC}}$ is not calculated correctly, but the reactive power set point of each generator is calculated correctly according to its own active power. Thus as illustrated in Fig. 11, unequal active powers (values are in p.u.) has no noticeable effect on the fixed power factor function.

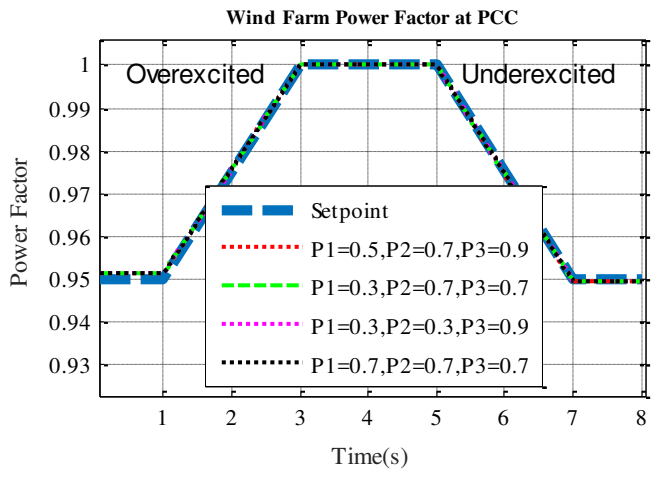

Fig. 11. Wind farm power factor considering different values for active power injections

\section{CONCULSION}

In this paper a decentralized control strategy for wind farms with full-scale converters is presented. In this strategy there is no need for the central control unit, measurement sensors at PCC and communication infrastructure. Thus, this method is 
cheaper and more reliable than the centralized power control. From the simulations it can be concluded that the proposed decentralized controller can lead to almost similar results of using a central control strategy. The biggest challenge for decentralized power control is to build an accurate model of the wind farm internal structure. Accurate parameterization of the transformers and cables are necessary, otherwise the reactive power may circulate among the generators although the requirements are met at PCC. Moreover, restructuring, environmental conditions and deterioration of materials may also influence the parameterization accuracy. The simulations also showed that deviations in fed-in active powers has no effect on the fixed power factor function. This decentralized controller can be extended to all reactive power control functions required by the grid operators such as $\mathrm{PF}(\mathrm{P})$ (power factor as a function of active power). It is also possible to extend this strategy to control a remote bus in radial distribution grids.

\section{ACKNOWLEDGMENT}

The research leading to these results has received funding from the Gesellschaft für Energie und Klimaschutz SchleswigHolstein GmbH (EKSH) doctoral studies grant as a part of the "Wind Park Control Strategies to Increase the Penetration of Wind Energy with Low Effects on the Electrical Grid" project.

\section{REFERENCES}

[1] I. Erlich, W. Winter, and A. Dittrich, "Advanced grid requirements for the integration of wind turbines into the German transmission system, " Proceedings of the IEEE Power Engineering Society General Meeting (PES '06), p. 7, June 2006.

[2] F. Blaabjerg, M. Liserre, and, K. Ma, "Power Electronics Converters for Wind Turbine Systems," IEEE Transactions on Industry Applications, vol. 48, no. 2, pp. 708-719, April 2012.

[3] B. R. Karthikeya, and R. J. Schutt. "Overview of wind park control strategies." IEEE Transactions on Sustainable Energy, vol. 5, no. 2, pp. 416-422, 2014

[4] Z. Chen, Z. Hao and S. Qin, "Centralized reactive power control for a wind farm under impact of communication delay.", International Journal of Control and Automation, vol. 7, no.2, pp. 85-98, 2014

[5] J. L. Rodriguez-Amenedo., S. Arnalte, and J. C. Burgos, "Automatic generation control of a wind farm with variable speed wind turbines," IEEE Transactions on Energy Conversion, vol. 17, no. 2, pp. 279-284, 2002.

[6] R. Teodorscu, M. Liserre, and P. Rodriguez, Grid Converters for Photovoltaic and Wind Power Systems, 3rd ed. John Wiley \& Sons, Ltd, 2011.

[7] M. Chinchilla, S. Arnaltes and J.C. Burgos, "Control of permanentmagnet generators applied to variable-speed wind-energy systems connected to the grid", IEEE Transactions on Energy Conversion, vol. 21, no. 1, pp. 130-135, 2006.

[8] D. Hansen, P. Sorensen, F. Iov and F. Blaabjerg, "Centralised power control of wind farm with doubly fed induction generators", Renew. Energy, vol. 31, no. 7, pp. 935-951, Jun. 2006.

[9] L. M. Fernandez, C. A. Garcia, and F. Jurado, "Comparative study on the performance of control systems for doubly fed induction generator (DFIG) wind turbines operating with power regulation," Energy, vol. 33, pp. 1438-1452, 2008.

[10] P. Flores, A. Tapia, and G. Tapia, "Application of a control algorithm for wind speed prediction and active power generation," Renewable Energy, vol. 30, pp. 523-536, Apr. 2005.

[11] J. M. Amada and M. P. C. Moreno, "Reactive Power Injection Strategies for Wind Energy Regarding its Statistical Nature", 6 th International
Workshop on Large-Scale Integration of Wind Power and Transmission Networks for Offshore Wind Farms, vol. 138, 2006.

[12] M. A. Chowdhury, N. Hosseinzadeh, M. M. Billah and S. A. Haque, "Dynamic DFIG wind farm model with an aggregation technique", 6 th International Conference on Electrical and Computer Engineering ICECE 2010 , pp. 330-333, 2010.

[13] V. Akhmatov, and H. Knudsen. "An aggregate model of a gridconnected, large-scale, offshore wind farm for power stability investigations-importance of windmill mechanical system." International Journal of Electrical Power \& Energy Systems, vol. 24, no. 9 , pp. 709-717, 2002.

[14] Technische Anschlussbedingungen für den Anschluss an das Mittelspannungsnetz-TAB Mittelspannung BDEW, May 2008. 